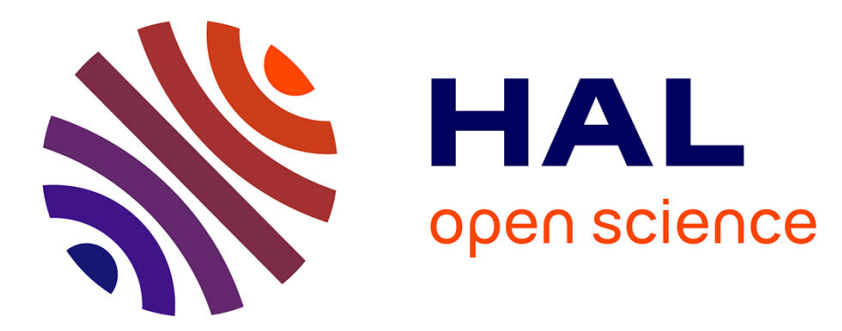

\title{
Metabolic adaptation of fungal strains in response to contamination by polychlorinated biphenyls
}

Sophie Perigon, Martin Massier, Joaquim Germain, Marie-Noëlle Binet, Nicolas Legay, Bello Mouhamadou

\section{- To cite this version:}

Sophie Perigon, Martin Massier, Joaquim Germain, Marie-Noëlle Binet, Nicolas Legay, et al.. Metabolic adaptation of fungal strains in response to contamination by polychlorinated biphenyls. Environmental Science and Pollution Research, 2019, 26 (15), pp.14943-14950. 10.1007/s11356-01904701-5 . hal-02478479

\author{
HAL Id: hal-02478479 \\ https://hal.science/hal-02478479
}

Submitted on 18 Feb 2020

HAL is a multi-disciplinary open access archive for the deposit and dissemination of scientific research documents, whether they are published or not. The documents may come from teaching and research institutions in France or abroad, or from public or private research centers.
L'archive ouverte pluridisciplinaire HAL, est destinée au dépôt et à la diffusion de documents scientifiques de niveau recherche, publiés ou non, émanant des établissements d'enseignement et de recherche français ou étrangers, des laboratoires publics ou privés. 


\section{Metabolic adaptation of fungal strains in response to contamination}

\section{by polychlorinated biphenyls}

Sophie Périgon ${ }^{\mathrm{a}}$, Martin Massier ${ }^{\mathrm{a}}$, Joaquim Germain ${ }^{\mathrm{a}}$, Marie-Noëlle Binet ${ }^{\mathrm{a}}$, Nicolas Legay ${ }^{\mathrm{b}}$, Bello Mouhamadou ${ }^{\mathrm{a}_{*}}$

${ }^{\text {a }}$ Laboratoire d'Ecologie Alpine, UMR 5553 CNRS / USMB Université Grenoble Alpes, 38058 Grenoble Cedex 9; France.

${ }^{\mathrm{b}}$ INSA Centre Val de Loire, Université de Tours, CNRS, UMR 7324 CITERES, 37200 Tours, France.

Highlights

- We investigated the metabolic potential of indigenous fungal strains in response to PCBs

- All these strains were tolerant to PCBs and able to efficiently degrade them whatever their origin

- This degradation seems to require different adaptation systems according to the strains

*Corresponding author. Tel: +33476635441

E-mail:bello.mouhamadou@univ-grenoble-alpes.fr Laboratoire d'Ecologie Alpine UMR 5553

CNRS / USMB Université Grenoble Alpes, 38058 Grenoble Cedex 9 ; France 


\section{Abstract}

Polychlorinated biphenyls (PCBs) represent a large group of recalcitrant environmental pollutants. Up to now, many studies have focused on bioremediation of PCBs by fungal strains; however the mechanisms of adaptation of these strains towards PCBs remain unknown despite their importance in developing effective bioremediation processes. We studied five species, each consisting of two strains isolated either from PCB -polluted or unpolluted substrates (control strains). We investigated their responses to PCB contamination by studying their tolerance to PCBs, their ability to reduce these pollutants and their expression level of Laccase genes. In Thermothelomyces thermophila, Thermothelomyces heterothallica, Thermoascus crustaceus and Fusarium solani, all the studied strains showed a similar tolerance and PCB degradation regardless of their origin. In Schizophyllum commune, while both strains showed similar resistance to PCBs i.e PCBs and their degradation products presented no toxicity for these strains, the rate of PCB degradation of the strain from a PCB-polluted environment was significantly slightly higher. The PCB degradation did not correlate with the expression level of genes encoding Laccases. These results demonstrate that the tolerance and PCB degradation by the fungal strains, which did not involve Laccase activities, required different adaptation systems which seem to be constitutive or rapidly inducible by PCB according to the fungal species.

Key words: Adaptation, Fungal species, PCBs, Tolerance, Biodegradation 


\section{Introduction}

Polychlorinated biphenyls (PCB) are organochlorine compounds consisting of biphenyl ring substituted by one or more chlorine atoms with 209 possible congeners that differ in the number of chlorine atoms and their position on the biphenyl ring (Marco-Urrea et al. 2015; Jitendra et al. 2017). Commercial PCB mixtures have been largely used from 1930 to the 1970s in industries with a large number of applications mainly in electrical equipment (Pieper and Seeger 2008; Passatore et al. 2014). Although their manufacture and marketing have been banned, PCBs remain persistent in the environment because of their high stability (Passatore et al. 2014). It is estimated that about 1 million tons have been produced worldwide and that about $30 \%$ of all manufactured PCBs have been released into the environment leading to soil and sediment contamination (UNEP 2011; Antolin-Rodriguez et al. 2016). PCBs represent a threat to ecosystem health due to their low degradability and high rate of toxicity, cause a wide range of toxic effects on animals and humans and are also considered as potentially carcinogenic (Brouwer et al. 1999; Pointing 2001; Dercova et al. 2009).

Although physicochemical technologies are available for the remediation of PCBcontaminated matrices, bioremediation using microorganisms offers a beneficial alternative with low environmental impact and reduced cost. Several model fungal species, in particular white-rot basidiomycetes, have been shown to efficiently degrade PCBs under laboratory conditions (RuizAguilar et al. 2002; Kamei et al. 2006). This capacity is linked to their rich and varied enzymatic systems, in particular extracellular and intracellular enzymes which, together, ensure efficient biodegradation of various xenobiotic pollutants (Harms et al. 2011; Passatore et al. 2014). However, despite their interesting metabolic potentialities, their application in the rehabilitation 
of polluted sites remains unsatisfactory due to their inability to develop on PCB polluted matrices probably resulting from the lack of competition in front of indigenous microbial community or their low tolerance to PCBs (Harms et al. 2011).

The use of indigenous fungal strains for bioremediation processes could turn out to be more efficient in comparison to model strains and is promising for environmental biotechnology (Sage et al. 2014). They are naturally selected by their environments and are able to develop in the presence of toxic xenobiotics (Marco-Urrea et al. 2015). These features are probably due to their physiological adaptation which could lead to the resistance to pollutants resulting in the change in their growth rates and spore production or their ecological adaptation affecting for example pigment production or their genetic adaptation sustained by change in the expression of genes involved in the pollutant degradation (Colpaert et al. 2000; Sharples et al. 2001; Zafra et al. 2015). Fungal metabolic adaptations at different biological levels in response to pollutants may vary according to the species and pollutants, and understanding the involved mechanisms is crucial for the development of an effective bioremediation strategy (Sharples et al. 2001; Garon et al. 2004; Zafra et al. 2015). While several studies focused on the screening of strains capable of effectively degrading PCBs (Tigini et al. 2009; Mouhamadou et al. 2013), to our knowledge, there are still no studies dealing with the mechanisms of indigenous fungal strains adaptation in response to PCBs.

The aim of this study was to investigate the responses of fungal strains to PCBs by focusing on their metabolic potential and on the expression of Laccase genes encoding nonspecific lignin degrading enzymes able to degrade a wide range of xenobiotic compounds (Harms et al. 2011; Viswanath et al. 2014). We used four Ascomycota species, Fusarium solani, Thermothelomyces thermophila, Thermothelomyces heterothallica and Thermoascus crustaceus and one Basidiomycota species, Schizophyllum commune. Each species consisted of two strains 
obtained from PCB-polluted and unpolluted substrates. The effects of strain origins were evaluated on the capacity of each strain to metabolize the mixture of 7 PCB congeners (Mouhamadou et al. 2013), on the tolerance of each strain and on the transcriptional level of Laccase genes.

\section{Materials and methods}

\section{PCBs}

The 7 PCB congeners PCB 28, 52, 101, 118, 138, 153, and 180 were obtained from Sigma Aldrich Corp. (St. Louis, MI, USA). A stock solution containing $15 \mathrm{mg}$ of each PCB in $105 \mathrm{ml}$ of DMSO was prepared.

\section{Fungal strains}

Soils from former industrial sites contaminated with PCBs were collected and fungal strains (Table 1) were isolated from these samples using the suspension / dilution method. For instance, $1 \mathrm{~g}$ of contaminated soil was added to $9 \mathrm{ml}$ of sterile water containing $0.05 \%$ of sodium dodecyl sulphate (w/v). After stirring, aliquots of the suspension were serially diluted and spread onto Petri dishes containing malt extract agar $(1.5 \%$ w/v) supplemented with $0.05 \%$ chloramphenicol. Cultures were incubated at $25^{\circ} \mathrm{C}$. After isolation, fungal strains were identified according to general principles of fungal classification (Ellis 1971 ; Booth, 1977a; Booth, 1977b; Domsch et al. 1980). References strains isolated from PCB unpolluted substrates belonged to the laboratory's collection (CMPG Collection Mycology Pharmacy Grenoble). 


\section{Analyses of PCB degradation}

The protocol concerning the biodegradation test was that described by Mouhamadou et al. (2013). Succinctly, the mycelium of each strain, grown in malt extract $(1.5 \% \mathrm{w} / \mathrm{v})$, was introduced into Erlenmeyer flasks containing $20 \mathrm{ml}$ of modified GS liquid medium (Galzy and Slonimski 1957) supplemented with glucose $\left(5 \mathrm{~g} \mathrm{l}^{-1}\right)$ and incubated at $25^{\circ} \mathrm{C}$ for Fusarium solani and S.chizophyllum commune or $37^{\circ} \mathrm{C}$ for Thermothelomyces thermophila, Thermothelomyces heterothallica and Thermoascus crustaceus on a rotary shaker (120 rpm). After $48 \mathrm{~h}$ incubation, the culture of each strain was spiked with $400 \mu$ l of a PCB mix giving a final concentration of 3 $\mu \mathrm{g}$ of each congener per ml. Each experiment containing each strain was performed in triplicate and included fungal-free flasks which are the abiotic controls. After 5 days incubation, the mycelium was separated from the culture medium by filtering through Whatman 40 filter.

\section{PCB extraction and HPLC analyses}

Culture medium and fungal mycelium were extracted separately. Culture medium was extracted three times with $20 \mathrm{ml}$ of hexane with agitation $(250 \mathrm{rpm}$, room temperature) for $30 \mathrm{~min}$. To minimize the phenomenon of PCB biosorption, mycelium was first homogenized in the serum bottles with a Potter homogenizer in $20 \mathrm{ml}$ of hexane, vigorously agitated for $10 \mathrm{~min}$ and incubated $24 \mathrm{~h}$ at room temperature with agitation $(250 \mathrm{rpm})$. The organic phases from culture medium and mycelium were evaporated under vacuum using a rotary evaporator and adjusted to a volume of $5 \mathrm{ml}$.

PCB analyses were performed in the "Institut de Chimie Moléculaire of Grenoble". Aliquots of $1 \mu \mathrm{L}$ from culture medium or from mycelium were analyzed using a gas chromatograph (5977-7890B), equipped with a HP-5MS 5 phenyl methyl silox column (ID: 0.25 mm, Length: $30 \mathrm{~m}$, Film: $0.25 \mathrm{~mm}$ ) and a quadrupole detector (Agilent Technologies USA). The 
carrier gas was helium. The injector temperature and the transfer line temperature were $250^{\circ} \mathrm{C}$ and $280^{\circ} \mathrm{C}$, respectively. The initial column temperature was $65^{\circ} \mathrm{C}$ held for $2 \mathrm{~min}$. The gradient

setting was $30^{\circ} \mathrm{C} \min ^{-1}$ to $240^{\circ} \mathrm{C}$, held for $2 \mathrm{~min}$ at $240^{\circ} \mathrm{C}$ then $10^{\circ} \mathrm{C} \mathrm{min}^{-1}$ to $340{ }^{\circ} \mathrm{C}$. The final temperature was $340^{\circ} \mathrm{C}$ held for $5 \mathrm{~min}$.

To determine the level of PCB removal, we determined the total residual PCB level in the fungal cultures by adding the residual levels of PCBs of the mycelium and of the culture medium and compared this rate with that of the abiotic control.

\section{Level expression of Laccase genes}

As the studied fungal species are described as laccase producers (Hamato et al. 1999; Wu et al. 2010; Rabot et al. 2011), we investigated the expression level of the genes encoding this enzyme. Each strain was cultivated in the presence of PCBs as described in the biodegradation test. In parallel, control cultures were carried out by incubating each strain only in the culture medium on the one hand and in the presence of DMSO on the other hand. After $7 \mathrm{~d}$ incubation, mycelium was recovered by filtering through Whatman 40 filters and $200 \mathrm{mg}$ of mycelium were used for the RNA extraction using FastRNA Spin kit (MP Biomedicals, France) according to the manufacturer's recommendations. Four $\mu \mathrm{g}$ of total RNA were reverse transcribed using the SuperScript III kit (Fisher Scientific) and subsequently, the RT products were amplified by specific primers designed in this study. These primers (Table 2) were defined by aligning orthologous sequences available in the Genbank database and encoding Laccases. From these alignments, we have targeted the conserved regions and defined couples of primers that could amplify DNA fragments of between 110 to $220 \mathrm{bp}$.

From these primers, the level expression on laccase gene was quantified via qPCR on an iQ5 system as described by Mouhamadou et al. (2017). cDNA of each strain obtained from the 
reverse transcription was mixed with $0.3 \mathrm{mM}$ of iQ SYBR Green supermix (Biorad, USA) and $0.3 \mathrm{mM}$ of each of the forward and reverse primers in a total volume of $25 \mu \mathrm{L}$. A melting curve analysis was performed to check for the unique presence of the targeted PCR product. For each species, a dilution series of the pooled PCR products from the two strains, precisely quantified using a qubit fluorometer (Invitrogen, USA), were run in tandem in qPCR with the cDNA of each strain. Each reaction was run in triplicate.

\section{Statistical analysis}

The effects of substrate origin, strain type and incubation type on the expression level of Laccase gene were tested using a three-way ANOVA. As strong interactions were found between the three explaining factors, we tested the effect of substrate origin and incubation type using a twoway ANOVA followed by least square difference post hoc tests. The effects of substrate origin and incubation type on the growth of mycelium were tested using a two-way ANOVA followed by Tukey's test. All the analyses were performed in R version 3.2.2 (R Core Team 2015), using the lsmeans (Lenth 2016) for least square difference post hoc tests and agricolae (de Mendiburu 2017) for Tukey post hoc test. When necessary, data were transformed to conform to assumptions of normality and homoscedasticity.

\section{Results}

\section{Tolerance of fungal strains to PCBs}

The study of the tolerance of each fungal strain to PCBs was performed by comparing the biomass weight formed during the culture of the strains in the presence / absence of PCBs. For 
each of the four Ascomycota species, no significant biomass differences were observed in fungal cultures in the presence / absence of PCBs according to the strain origin (Table 3). In the Basidiomycota species Schizophyllum commune (Table 3), the strain isolated from PCB-polluted substrate showed no difference in biomass in the presence / absence of PCBs, whereas in that from unpolluted substrate, despite the positive effect of the solvent on the growth of this strain, there was no significant difference in its growth in the presence / absence of PCBs.

\section{PCB removal by fungal strains}

We determined the percentage of depletion of PCBs by comparing the quantity of residual PCBs in the culture medium and in the mycelium (biosorption) of each strain with the quantity of residual PCBs in abiotic control. All strains were able to efficiently reduce PCBs. In Ascomycota, strains of the same species showed no significant differences in the rate of PCB removal. It ranged from $84.79 \%$ to $88.11 \%$ in Fusarium solani, from $79.86 \%$ to $86.61 \%$ in Thermothelomyces heterothallica, from $95.22 \%$ to $95.91 \%$ in Thermoascus crustaceus and from 93.44\% to $94.64 \%$ in Thermothelomyces thermophila. In the Basidiomycota, Schizophyllum commune, the two studied strains isolated from unpolluted and PCB polluted substrates reduced PCBs at $80.91 \%$ and $86.20 \%$, respectively, but these rates are significantly different $(\mathrm{F}=16.93$; $\mathrm{p}=0.015)$.

\section{Expression level of Laccase genes}

Primers were defined to investigate the expression level of Laccase transcripts. With these primers, using the genomic DNA of each strain as template, only the results of Thermothelomyces heterothallica could not be obtained. For the other strains, one specific PCR product was obtained at the expected size indicating the amplification of a single Laccase gene. 
Results of RT-qPCR (Fig. 1) showed that the expression level of Laccase gene was significantly different between strains $(\mathrm{F}=13185 ; \mathrm{p}<0.001)$ with the following patterns Thermoascus crustaceus $<$ Thermothelomyces thermophila $<$ Schizophyllum commune $<$ Fusarium solani. The three-way ANOVA showing strong interactions $(\mathrm{F}=6.45 ; \mathrm{p}<0.001)$ between substrate origin (PCB-unpolluted $v s$ PCB-polluted), strain type and incubation type (control vs solvent $v s$ PCB), we realized two-way ANOVA for each strain to disentangle substrate origin and incubation type effects (Table 4). In Fusarium solani, only a substrate origin effect was observed (Table 4) with a higher expression level of Laccase gene in PCB-polluted substrates (Fig. 1). In the three other strains, strong interactive effects were observed (Table 4) but with different patterns (Fig. 1). For Thermothelomyces thermophila, the expression level of Laccase gene was lower in the presence of PCBs in the strains isolated from PCB-polluted substrates than in those from PCB-unpolluted substrates (Fig. 1). For Thermoascus crustaceus, the expression level of Laccase gene was higher in the presence of PCBs than in the absence of PCBs in the strain isolated from PCB-unpolluted substrate but was similar to all other treatments (Fig. 1). For Schizophyllum commune, the expression level of Laccase gene was lower in the strains isolated from PCB-polluted substrate than in those from PCB-unpolluted substrates. In these PCB-polluted substrates, the expression level of Laccase gene was higher in the presence than in absence of PCBs (Fig. 1).

Finally, the interactions between the rate of PCB removal and the expression level of Laccase gene were studied using a linear regression analysis and no correlation was found between whatever the fungal species studied (Fig 2). 


\section{Discussion}

Up to now, the mechanisms of adaptation of fungal strains to PCBs remain unknown and yet important to develop effective bioremediation processes. To bridge this gap, we investigated the responses of four Ascomycota and one Basidiomycota species towards PCBs by examining their tolerance, their ability to reduce these pollutants and the expression level of gene encoding Laccases, non-specific enzymes involved in the biodegradation of environmental pollutants. Each species consisted in two strains provided from PCB -polluted and unpolluted substrates.

All the studied strains showed high efficiency in PCB removal in liquid medium comparable to that obtained with basidiomycete ligninolytic fungi (Kubatova et al. 2001; Kamei et al. 2006 ; Cvancarova et al. 2012 ; Federici et al. 2012) or autochthonous strains isolated from highly polluted PCB substrates (Tiggini et al. 2009; Mouhamadou et al. 2013). First, we considered that the substantial losses of PCBs were essentially due to the fungal biodegradation as reported by Mouhamadou et al. (2013) since the extraction of PCBs from the mycelium corresponding to the fungal biosorption was drastic by crushing the mycelium in hexane and by incubating it $24 \mathrm{~h}$ in hexane with vigorous agitation. Second, in the four species belonging to Ascomycota, we did not detect any effects of the origin of strains on their resistance to PCBs and their ability to degrade PCBs. These results seem to rule out or to minimize the need of prior adaptation of the studied strains towards PCBs for its degradation. Comparable trends, characterizing white rot fungi, had also been reported in some species belonging to Zygomycota where strains isolated from polycyclic aromatic hydrocarbons (PAH) contaminated soils had an equivalent efficiency of PAH biodegradation in comparison to that of the same species isolated from PAH uncontaminated soils (Garon et al. 2004). It is possible to speculate that the systems of resistance / degradation of PCBs seem to be constitutive or rapidly inducible by PCBs as 
described in bacterial communities which adapt rapidly to new xenobiotics through for example, the acquisition of mobile genetic elements (Top et al. 2003).

In the Basidiomycota Schizophyllum commune, the fact that both strains reduce PCBs at a rate higher than $80 \%$, regardless of their origin would suggest that they would probably bear a constitutive mechanism of PCB-biodegradation. However, a slightly greater efficiency in the PCB biodegradation of the strain isolated from PCB-contaminated habitat $v s$ control strain suggests either individual variation in the biodegradation that may involve two catabolic pathways with different efficiencies or an adaptation to the PCBs enhancing the efficiency of the strain from PCB-polluted habitat. The latter hypothesis could be excluded as both strains exhibited the same resistance to PCBs.

We investigated the expression level of one of the Laccase genes to examine the possible link between resistance / PCB degradation observed in the studied strains and this enzymatic activity. We found that 8 out of the 10 analyzed strains expressed the genes. In Thermothelomyces heterothallica, we were unable to obtain amplification products corresponding to this gene probably because of the non-specificity of our primers. The transcript level of the Laccase gene did not correlate with PCB removal. We hypothesized that this enzymatic activity was not involved in PCB biodegradation, consistent with studies which challenge the implication of Laccase in the fungal PCB biodegradation (Tigini et al. 2009; Plackova et al. 2012). In addition, the variability in the expression of this gene in the studied strains confirms this hypothesis and is in line with studies which demonstrated that some Laccase genes were down or up-regulated by xenobiotics while the others were constitutively expressed (Careno and Roncero 2007). This suggests that the transcripts detected in our study were probably expressed from different genes. 
Our study showed that all the studied fungal strains were tolerant to PCBs and able to efficiently degrade them in liquid medium whatever their origin. This degradation, which did not involve the Laccase activities, seems to require different adaptation systems according to the strains. Further studies are needed to demonstrate such adaptation systems across a large number of fungal species. These could be of interest for optimizing the use of fungal strains in environmental biotechnology.

\section{Acknowledgments}

This research was financed by UMR 5553 CNRS/UGA "Projet interne". We are deeply grateful to Viviane Barbreau for her critical reading of the manuscript and interesting remarks. We address our special thanks to Nael Mouhamadou, Ilian Mouhamadou and Lila Mouhamadou for their help and unconditional support.

\section{References}

Antolin-Rodriguez JM, Sánchez-Báscones M, Martin-Ramos P, Bravo-Sanchez C (2016) Estimation of PCB content in agricultural soils associated with long-term fertilization with organic waste. Environmental Science and Pollution Research 23 : 12372-12383.

Booth C (1977a) Fusarium Laboratory Guide to the Identification of the Major Species. Commonwealth Mycological Institute, UK.

Booth C (1977b) The Genus Fusarium. Commonwealth Mycological Institute, Kew, Surrey

Brouwer A,Longnecker MP,Birnbaum LS,Cogliano J,Kostyniak P, Moore J,Schantz S,Winneke G (1999) Characterization of Potential Endocrine-Related Health Effects at Low-Dose Levels of Exposure to PCBs. Environmental Health Perspectives 107 : 639-649 
Canero DC, Roncero MIG (2008) Functional Analyses of Laccase Genes from Fusarium oxysporum. Phytopathology 98: 509-518

Colpaert JV, Vandenkoornhuyse P, Adriaensen K, Vangronsveld J (2000) Genetic variation and heavy metal tolerance in the ectomycorrhizal basidiomycete Suillus luteus. New Phytologist 147: 367379

Core Team R, 2015. R: a language and environment for statistical computing. R Foundation for Statistical Computing, Vienna

Cvancarova MC, Kresinova Z, Alena Filipova A, Covino AS, Cajthaml T (2012) Biodegradation of PCBs by ligninolytic fungi and characterization of the degradation products. Chemosphere 88 : $1317-1323$

de Mendiburu F, 2017. agricolae: Statistical Procedures for Agricultural Research. R package version 1.2-8. https://CRAN.R-project.org/package=agricolae

Dercova K, Seligova J, Dudasova H, Mikulasova M, Silharova K,Tothova L, Hucko P (2009) Characterization of the bottom sediments contaminated with polychlorinated biphenyls: evaluation of ecotoxicity and biodegradability. International Biodeterioration and Biodegradation 63: 440-449.

Ellis MB (1971) Dematiaceous Hyphomycetes, Principal Mycologist. Commonwealth Mycological Institute, Kew.

Federici E, Giubilei M, Santi G, Zanaroli G, Negroni A, Fava F, Petruccioli M, D’Annibale A (2012) Bioaugmentation of a historically contaminated soil by polychlorinated biphenyls with Lentinus tigrinus. Microbial Cell Factories 23: 11-35

Galzy P, Slonimski P (1957) Variations physiologiques de la levure au cours de la croissance sur l'acide lactique comme seule source de carbone. Comptes Rendus de l'Academie des Sciences 245D: 2423-2426 
Garon D, Sage L, Seigle-Murandi F (2004) Effects of fungal bioaugmentation and cyclodextrin amendment on fluorine degradation in soil slurry. Biodegradation 15: 1-8

Harms H, Schlosser D, Wick LY (2011) Untapped potential: exploiting fungi in bioremediation of hazardous chemicals. Nature Reviews Microbiology 9: 177-192

Kamei I, Kogura R, Kondo R (2006) Metabolism of 4,40-dichlorobiphenyl by white-rot fungi Phanerochaete chrysosporium and Phanerochaete sp. MZ142. Applied Microbiology and Biotechnology 72: 566-575

Kireeva NA, Bakaeva MD, Galimzyanova NF (2008) Evaluation of the Effect of Various Methods of Oil-Polluted Soil Bioremediation on Micromycete Complexes. Applied Biochemistry and Microbiology 44: 55-59

Kubatova A, Erbanova P, Eichlerova I, Homolka L, Nerud F, Sasek V (2001) PCB congener selective biodegradation by the white rot fungi Pleurotus ostreatus in contaminated soil. Chemosphere 43: $207-215$

Lenth RV (2016) Least-squares means: the R package lsmeans. J Stat Softw 69: 1-33

Marco-Urrea E, Inmaculada Garcia-Romera I, Aranda E (2015) Potential of non-ligninolytic fungi in bioremediation of chlorinated and polycyclic aromatic hydrocarbons. New Biotechnology 32: $620-628$

Mouhamadou B, Faure M, Sage L, Marçais J, Souard F, Geremia R (2013) Potential of autochthonous fungal strains isolated from contaminated soils for degradation of polychlorinated biphenyls. Fungal Biology 117: 268-274

Mouhamadou B, Sage L, Perigon S, Seguin V, Bouchart V, Legendre P, Caillat M, Yamounia H, Garon D (2017) Molecular screening of xerophilic Aspergillus strains producing mycophenolic acid. Fungal Biology 121: 103-111 
Passatore L, Rossettic S, Juwarkard AA, Massacci A (2014) Phytoremediation and bioremediation of polychlorinated biphenyls (PCBs): State of knowledge and research perspectives. Journal of Hazardous Materials 278: 189-202

Pieper DH, Seeger MJ (2008) Bacterial metabolism of polychlorinated biphenyls. Journal of Molecular Microbiology and Biotechnology 15: 121-138

Plackova M, Svobodova K, Cajthaml T (2012) Laccase activity profiling and gene expression in PCBdegrading cultures of Trametes versicolor. International Biodeterioration \& Biodegradation 71: $22-28$

Pointing SB (2001) Feasibility of bioremediation by white rot fungi. Applied Microbiology and Biotechnology 57: 20-33

Ruiz-Aguilar GML, Fernandez-Sanchez JM, Rodriguez-Vazquez R, Poggio-Varaldo H (2002) Degradation by white-rot fungi of high concentrations of PCB extracted from a contaminated soil. Advances in Environmental Research 6: 559-568

Sage L, Périgon S, Faure M, Gaignaire C, Abdelghafour M, Mehu J, Geremia RA, Mouhamadou B (2014) Autochthonous ascomycetes in depollution of polychlorinated biphenyls contaminated soil and sediment. Chemosphere 110: 62-69

Jitendra K. Sharma, Ravindra K. Gautam, Sneha V. Nanekar, Roland Weber Brajesh K. Singh, Sanjeev K. Singh, Juwarkar AA (2017) Advances and perspective in bioremediation of polychlorinated biphenyl-contaminated soils. Environ Sci Pollut Res doi: 10.1007/s11356-017-8995-4

Sharples JM, Meharg AA, Chambers SM, Cairney JWG (2001) Arsenate resistance in the ericoid mycorrhizal fungus Hymenoscyphus ericae. New Phytologist 151: 265-270

Tigini V, Prigione V, Di Toro S, Fava F, Varese GC (2009) Isolation and characterization of polychlorinated biphenyl (PCB) degrading fungi from a historically contaminated soil. Microbial Cell Factories 8: 5. 
Top EM, Springae D (2003) The role of mobile genetic elements in bacterial adaptation to xenobiotic organic compounds. Current Opinion in Biotechnology 14: 262-269

UNEP (United Nations Environment Program) (2011) Report of the conference of the parties to the stockholm convention on persistent organic pollutants on the work of its fifth meeting, 5th edn., Geneva, Switzerland

Viswanath B, Rajesh B, Janardhan A, Kumar AP, Narasimha G (2014) Fungal laccases and their applications in bioremediation. Enzyme Research 2014: 163242

Zafra G, Absalón AE, Cortés-Espinosa DV (2015) Morphological changes and growth of filamentous fungi in the presence of high concentrations of PAHs. Brazilian Journal of Microbiology 46: 937941 
Figure 1. Transcript level of the Laccase genes in the four studied fungal strains.

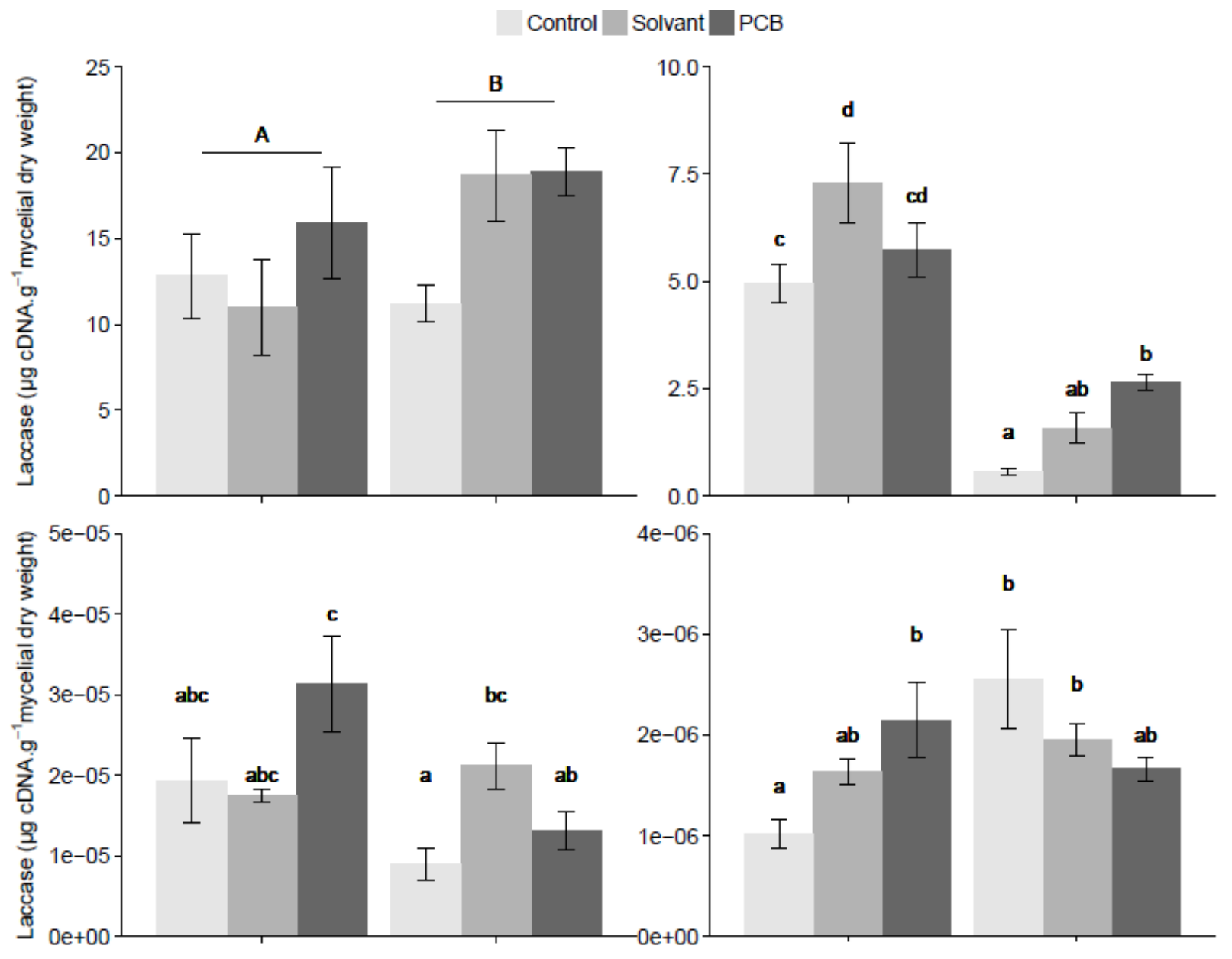


Figure 2. Relationship between PCB biodegradation and level expression of the laccase genes.
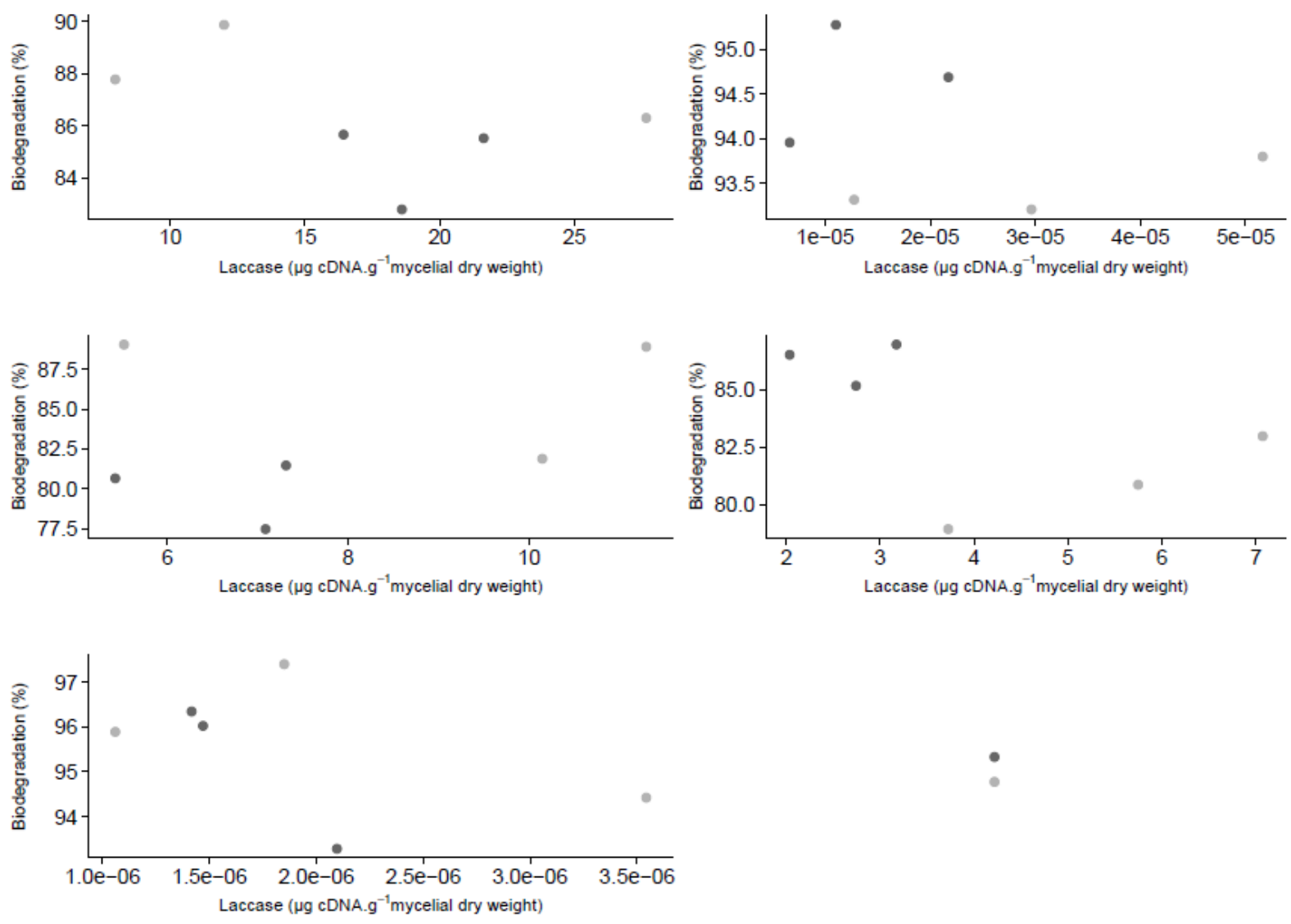
Table 1. Fungal strains used in this study. The concentrations of PCBs in polluted soil are indicated.

\begin{tabular}{|c|c|c|c|c|}
\hline Species & Strains & $\mathbf{N}^{\circ}$ culture collection & Origin & $\begin{array}{l}\text { PCB concentration } \\
\mathrm{mg} / \mathrm{g} \text { dry soil }\end{array}$ \\
\hline Fusarium solani & Fs-US & CMPG 542 & Soil, Rhone-Alpes, France & 0 \\
\hline \multirow[t]{2}{*}{ Thermothelomyces heterothallica } & Th-US & CMPG 1495 & Sediment, Normandie, France & 0 \\
\hline & Th-PS & CMPG 2144 & Soil, Lorraine, France & 3000 \\
\hline \multirow[t]{2}{*}{ Thermothelomyces thermophila } & Tt-US & CMPG 1946 & Soil, Lorraine, France & 0 \\
\hline & Tt-PS & CMPG 1989 & Soil, Lorraine, France & 320 \\
\hline \multirow[t]{2}{*}{ Thermoascus crustaceus } & Tc-US & CMPG 2191 & Sediment, Normandie, France & 0 \\
\hline & Tc-PS & CMPG 1881 & Soil, Lorraine, France & 320 \\
\hline Schizophyllum commune & Sc-PS & CMPG 2165 & Soil, Lorraine, France & 3000 \\
\hline
\end{tabular}


Table 2. Primers used for the amplification of laccase genes

\begin{tabular}{|c|c|c|c|}
\hline \multirow[t]{2}{*}{ Studied species } & \multicolumn{2}{|c|}{ Genbank orthologous sequences } & \multirow[t]{2}{*}{ Primers } \\
\hline & Target species & $\mathrm{N}^{\circ}$ accession number & \\
\hline F. solani & $\begin{array}{l}\text { Nectria haematococca } \\
\text { F. solani }\end{array}$ & $\begin{array}{l}\text { XM_003050908.1 } \\
\text { KF728747.1 }\end{array}$ & $\begin{array}{l}\text { FsFoward: TACGGCACCACATGGTATC } \\
\text { TsReverse: CCGACATCAACATCGTAGT }\end{array}$ \\
\hline $\begin{array}{l}\text { Th. thermophila } \\
\text { Th. heterothallica }\end{array}$ & $\begin{array}{l}\text { Th. thermophila } \\
\text { Chaetomium globosum } \\
\text { Melanocarpus albomyces }\end{array}$ & $\begin{array}{l}\text { XM_003663693.1 } \\
\text { XM_001228805.1 } \\
\text { AJ571698.1 }\end{array}$ & $\begin{array}{l}\text { MFoward: TCGCTCGTCAACCACAC } \\
\text { MReverse: GTAGTGGAAGATGGCGG }\end{array}$ \\
\hline S. commune & $\begin{array}{l}\text { S. commune } \\
\text { Trametes versicolor }\end{array}$ & $\begin{array}{l}\text { XM_003029116.1 } \\
\text { HM137002.1 }\end{array}$ & $\begin{array}{l}\text { ScFoward: TCGAGCATGGAAAGCGCT } \\
\text { ScReverse: TCCGCCTCAATGATGGTC }\end{array}$ \\
\hline T. crustaceus & $\begin{array}{l}\text { Rasamsonia emersonii } \\
\text { Colletotrichum orbiculare } \\
\text { Phialocephala scopiformis }\end{array}$ & $\begin{array}{l}\text { XM_013470980.1 } \\
\text { AB713188.1 } \\
\text { XM_018212529.1 }\end{array}$ & $\begin{array}{l}\text { TcFoward: CATGGTCCGATGGCGTCCC } \\
\text { TcReverse: TGCCGTATTGAGTAGCAGTCC }\end{array}$ \\
\hline
\end{tabular}


Table 3. Influence of PCBs on the growth of fungal strains.

The results are expressed as means (mg/dry mycelium) \pm standard deviation. Similar letters indicate no significant difference

\begin{tabular}{|c|c|c|c|c|c|c|}
\hline & \multicolumn{3}{|c|}{ Strains from unpolluted substrate } & \multicolumn{3}{|c|}{ Strains from PCB polluted substrate } \\
\hline & Control & Solvent & PCB & Control & Solvent & PCB \\
\hline Fusarium solani & $7.91 \pm 0.04^{\mathrm{A}}$ & $9.99 \pm 1.05^{\mathrm{A}}$ & $9.15 \pm 0.29^{\mathrm{A}}$ & $10.11 \pm 0.85^{\mathrm{A}}$ & $10.80 \pm 0.44^{\mathrm{A}}$ & $10.34 \pm 0.51^{\mathrm{A}}$ \\
\hline Thermothelomyces heterothallica & $10.52 \pm 0.61^{\mathrm{A}}$ & $9.26 \pm 0.59^{\mathrm{A}}$ & $9.82 \pm 0.38^{\mathrm{A}}$ & $10.45 \pm 0.41^{\mathrm{A}}$ & $12.81 \pm 0.98^{\mathrm{A}}$ & $13.29 \pm 1.03^{\mathrm{A}}$ \\
\hline Thermothelomyces thermophila & $28.28 \pm 0.6^{\mathrm{A}}$ & $26.71 \pm 4.6^{\mathrm{A}}$ & $25.29 \pm 2.45^{\mathrm{A}}$ & $28.07 \pm 4.43^{\mathrm{A}}$ & $30.40 \pm 0.96^{\mathrm{A}}$ & $29.13 \pm 0.94^{\mathrm{A}}$ \\
\hline Thermoascuc crustaceus & $17.40 \pm 0.46^{\mathrm{A}}$ & $16.49 \pm 0.92^{\mathrm{A}}$ & $14.63 \pm 0.67^{\mathrm{A}}$ & $18.07 \pm 0.86^{\mathrm{A}}$ & $19.80 \pm 0.86^{\mathrm{A}}$ & $16.63 \pm 0.95^{\mathrm{A}}$ \\
\hline Schizophyllum commune & $7.045 \pm 0.44^{\mathrm{AB}}$ & $9.72 \pm 2.07^{\mathrm{A}}$ & $4.05 \pm 1.04^{\mathrm{B}}$ & $4.89 \pm 0.90^{\mathrm{A}}$ & $6.23 \pm 0.91^{\mathrm{A}}$ & $6.64 \pm 0.52^{\mathrm{A}}$ \\
\hline
\end{tabular}


Table 4. Effects of soil origin and incubation type on the expression level of Laccase gene of four fungal strains. For each treatment, F-values and p-values of ANOVAs were given. Significant differences are highlighted in bold type.

\begin{tabular}{lcccccc}
\hline & \multicolumn{2}{c}{ Soil origin } & \multicolumn{2}{c}{ Incubation type } & \multicolumn{2}{c}{ Strain x Incubation } \\
& $\mathrm{F}$ & $p$ & $\mathrm{~F}$ & $p$ & $\mathrm{~F}$ & $p$ \\
\hline $\begin{array}{l}\text { Fusarium solani } \\
\text { Thermothelomyces }\end{array}$ & 5.95 & $\mathbf{0 . 0 1 8}$ & 2.54 & 0.089 & 2.41 & 0.101 \\
thermophila & 6.06 & $\mathbf{0 . 0 1 8}$ & 4.23 & $\mathbf{0 . 0 2 1}$ & 3.75 & $\mathbf{0 . 0 3 1}$ \\
$\begin{array}{l}\text { Schizophyllum commune } \\
\text { Thermoascus crustaceus }\end{array}$ & 118.46 & $\mathbf{< 0 . 0 0 1}$ & 6.59 & $\mathbf{0 . 0 0 3}$ & 3.52 & $\mathbf{0 . 0 3 8}$ \\
\hline
\end{tabular}

